\title{
Th1-type responses mediate spontaneous ileitis in a novel murine model of Crohn's disease
}

\author{
Michele M. Kosiewicz, ${ }^{1}$ Cynthia C. Nast, ${ }^{2}$ Anasuya Krishnan, ${ }^{1}$ Jesus Rivera-Nieves, ${ }^{1}$ \\ Christopher A. Moskaluk, ${ }^{1}$ Satoshi Matsumoto, ${ }^{3}$ Kosuke Kozaiwa, ${ }^{1}$ and Fabio Cominelli ${ }^{1}$
}

${ }^{1}$ Departments of Medicine and Pathology, University of Virginia Health System, Charlottesville, Virginia, USA
${ }^{2}$ Department of Surgical Pathology, Cedars-Sinai Medical Center, Los Angeles, California, USA
${ }^{3}$ Yakult Central Institute for Microbiological Research, Tokyo, Japan

Address correspondence to: Fabio Cominelli, Division of Gastroenterology and Hepatology, University of Virginia Health System, PO Box 800708, Charlottesville, Virginia 22908, USA. Phone: (804) 243-6400; Fax: (804) 243-6405; E-mail: fc4q@virginia.edu.

M.M. Kosiewicz's present address is: Department of Microbiology and Immunology, University of Louisville Health Sciences Center, Louisville, Kentucky, USA.

Received for publication August 4, 2000, and accepted in revised form February 5, 2001.

\begin{abstract}
We describe here the immunologic characterization of a new mouse strain, SAMP1/Yit, which spontaneously develops a chronic intestinal inflammation localized to the terminal ileum. The resulting ileitis bears a remarkable resemblance to human Crohn's disease. This strain of mice develops discontinuous, transmural inflammatory lesions in the terminal ileum with $100 \%$ penetrance by 30 weeks of age. The intestinal inflammation is characterized by massive infiltration of activated $\mathrm{CD} 4^{+}$and $\mathrm{CD} 8 \alpha^{+} \mathrm{TCR} \alpha \beta^{+}$ $T$ cells into the lamina propria and is accompanied by a dramatic decrease in the intraepithelial lymphocyte $\mathrm{CD} 8 \alpha^{+} \mathrm{TCR} \gamma \delta^{+} / \mathrm{CD} 8 \alpha^{+} \mathrm{TCR} \alpha \beta^{+}$ratio. The results of adoptive transfer experiments strongly suggest that $\mathrm{CD}^{+} \mathrm{T}$ cells that produce a Th1-like profile of cytokines, e.g., IFN- $\gamma$ and TNF, mediate the intestinal inflammation found in SAMP1/Yit mice. In addition, pretreatment of adoptive transfer recipients with a neutralizing anti-TNF antibody prevents the development of intestinal inflammation, suggesting that TNF plays an important role in the pathogenesis of intestinal inflammation in this model. To our knowledge, these data provide the first direct evidence that Th1-producing $T$ cells mediate intestinal inflammation in a spontaneous animal model of human Crohn's disease.
\end{abstract}

J. Clin. Invest. 107:695-702 (2001).

\section{Introduction}

Crohn's disease (CD) is a chronic inflammatory bowel disease (IBD) of unknown etiology that can occur in any part of the gastrointestinal tract, but most frequently in the small intestine (1). Although there is increasing evidence that genetic, immunologic, and environmental factors may be involved, the precise etiology and pathogenic mechanisms of disease remain unclear (1-5). Until recently, progress in understanding the pathogenesis of $\mathrm{CD}$ has been seriously hindered by a lack of animal models that faithfully resemble human disease. With the advent of new technologies, several animal models of IBD have recently been described (6-8). Most affect the large bowel rather than the small intestine and are artificially generated by immunologic, genetic, or chemical manipulation. Although these models have provided useful information concerning basic mechanisms of intestinal inflammation, they do not develop spontaneously and lack many of the important characteristics of $\mathrm{CD}$ (e.g., specific histological features, presence of ileitis, and maintenance of chronic inflammation). Therefore, these models may have limited value for investigating the precise etiopathogenesis of human CD (9).
The SAMP1/Yit mouse is a unique model of intestinal inflammation. This model develops a spontaneous and chronic ileitis that closely resembles human $\mathrm{CD}$ in the absence of chemical, immunologic, or genetic manipulations (10). Here, we first describe the remarkable similarities between this model and human CD with regard to disease location and histological findings. Second, we report that Th1-type $T$ cells from SAMP1/Yit mice can adoptively transfer disease. Last, we show that these pathogenic $T$ cells directly mediate the resulting ileitis through a mechanism that may require TNF production. These findings demonstrate that pathogenic Th1-type T cells can mediate a Crohn'slike disease in a spontaneous mouse model of ileitis.

\section{Methods}

Animals. We have established a colony of SAMP1/Yit mice in a barrier facility at the University of Virginia from animals provided by S. Matsumoto (Yakult Central Institute for Microbiological Research, Tokyo, Japan). The SAMP1/Yit $\left(\mathrm{H}-2^{\mathrm{k}}\right)$ mouse strain was originally derived from AKR mice (original parents purchased from The Jackson Laboratories, Bar Harbor, 
Maine, USA) (10). Analysis of SAMP1/Yit genomic DNA with a panel of 274 mapped microsatellite loci confirmed the strain to be inbred. At least $40 \%$ of the alleles, distributed widely throughout the genome, did not appear to derive from the AKR/J strain. However, the entire MHC region on chromosome 17 was identical to that of AKR/J mice (11).

For the purposes of these experiments, AKR and 6- to 8-week-old severe-combined immunodeficient (SCID; C3HSmn.C-Prkdcsid/J) mice were purchased from The Jackson Laboratories. Total DNA was routinely extracted from fecal samples and analyzed for the presence of Helicobacter hepaticus and Helicobacter bilis using PCR with species-specific primers. Serum and fecal samples from SAMP1/Yit mice with intestinal lesions were consistently found to be negative for these organisms.

Harvest of intraepithelial lymphocytes and lamina propria lymphocytes. For the preparation of intraepithelial lymphocytes (IELs) and lamina propria lymphocytes (LPLs), intestines were rinsed in ice-cold PBS, cut into 2- to 5$\mathrm{mm}$ pieces, and placed in a mixture of HBSS/DTT (1 $\mathrm{mM}$ ) for 1 hour at $37^{\circ} \mathrm{C}$. This procedure was repeated three times, and supernatants (containing the IELs) were collected and pooled. IELs were separated using a $20 \% / 40 \% / 70 \%$ discontinuous Percoll gradient and recovered from the $40 \% / 70 \%$ interface. To prepare LPLs, the intestinal tissue remaining after IEL isolation was minced and treated with dispase $(1.5 \mathrm{mg} / \mathrm{ml})$. LPLs were then separated on a $20 \% / 40 \% / 70 \%$ discontinuous Percoll gradient and collected from the $40 \% / 70 \%$ interface.

T-cell enrichment and cell separation. T cells were enriched by negative selection using T-cell affinity columns (R\&D Systems, Minneapolis, Minnesota, USA). For subpopulation separation, $\mathrm{CD}^{+} \mathrm{T}$ cells were either negatively selected using $\mathrm{CD}^{+} \mathrm{T}$ cell columns (R\&D Systems) or positively selected by incubation with anti-CD4-bound magnetic beads, and then sorted into their respective populations using a magnetic cell-sorting system (Miltenyi Biotec, Auburn, California, USA).

Cell culture. Cells were cultured either unfractionated or after enrichment for $\mathrm{CD}^{+}{ }^{+} \mathrm{T}$ cells. To stimulate $\mathrm{T}$ cells with immobilized anti-CD3, 24-well plates were incubated with $10 \mu \mathrm{g} / \mathrm{ml}$ of anti-CD3 and/or CD28 antibody (PharMingen, San Diego, California, USA) for 90 minutes at $37^{\circ} \mathrm{C}$ and washed three times with PBS. Mesenteric lymph node (MLN; $2 \times 10^{6}$ cells $/ \mathrm{ml}$ ) in complete media (RPMI with 10\% FCS, $2 \mathrm{mM}$ L-glutamine, $100 \mathrm{U}$ penicillin, $100 \mathrm{mg} / \mathrm{ml}$ streptomycin, $10 \mathrm{mM}$ HEPES, $1 \mathrm{mM}$ sodium pyruvate, nonessential amino acids, $1 \times 10^{5} \mathrm{M} 2 \mathrm{ME}$ ) were cultured for 24 , 48, 72 , or 96 hours, and supernatants were harvested for analyses.

Flow cytometry. Cells in suspension were labeled with fluorochrome-tagged antibodies, including anti-CD3, CD4, CD8, TCR $\alpha \beta$, TCR $\gamma \delta$, CD69, CD25 and CD62L (PharMingen), CD44 and CD45RB (Caltag Laboratories, Burlingame, California, USA). Cells were analyzed after fixation with $2 \%$ formalin. To determine the percentage of cells expressing surface markers and the intensity of expression, two- and three-color analyses were per- formed using the FACS system (Becton-Dickinson Immunocytometry Systems, San Jose, California, USA).

Cytokine ELISAs. IFN- $\gamma$, TNF, IL-4, and IL-10 were measured by ELISA, using commercially available recombinant cytokines and antibodies (PharMingen). Briefly, $1 \mu \mathrm{g} / \mathrm{ml}$ of capture antibody in carbonate buffer was added to flat-bottom 96-well microplates. After incubation at room temperature for 4 hours, wells were blocked overnight at $4^{\circ} \mathrm{C}$ with $2 \%$ BSA in BBS. Samples were distributed and incubated for 8 hours at $4^{\circ} \mathrm{C}$. Detecting biotinylated antibody $(1 \mu \mathrm{g} / \mathrm{ml})$ was added to each well, and after 1 hour of incubation at room temperature, avidin-conjugated alkaline phosphatase was added. Samples were incubated for 30 minutes at room temperature. Paranitrophenyl substrate at $1 \mathrm{mg} / \mathrm{ml}$ in 1 $M$ diethylamine buffer was then added to each well, and OD was measured at $405 \mathrm{~nm}$ after incubation at room temperature for varying amounts of time.

Adoptive transfer experiments. Adult female MHCmatched SCID mice were used as recipients in the following experiments. SAMP1/Yit or AKR (control) mice were euthanized at 30 weeks of age. MLN cells were harvested and rendered into a single-cell suspension. SCID mice were injected intraperitoneally with $1 \times 10^{5}, 5 \times 10^{5}$, or $1 \times 10^{6}$ unfractionated or $\mathrm{CD}^{+} \mathrm{T}$ cell-enriched MLN cells. Mice were euthanized 2, 4, or 6 weeks after injection. Intestinal tract and MLN cells were harvested. MLN cells were cultured, and cytokine production was measured. The duodenum, jejunum, and ileum were removed and evaluated histologically in a blinded fashion by a single pathologist (C.C. Nast). Two 1.5-cm sections of small bowel were completely assessed. Acute and chronic inflammation were assessed separately using a semiquantitative $0-4+$ score as follows: acute inflammatory score $0=0-1$ polymorphonuclear cells per high power field (PMN/hpf); 1 = 2-10 PMN/hpf within mucosa; 2 = 11-20 PMN/hpf within mucosa; 3 = 21-30 PMN/hpf within mucosa or 11-20 PMN/hpf with extension below muscularis mucosae; 4 = >30 PMN/hpf within mucosa or >20 PMN/hpf with extension below muscularis mucosae. Chronic inflammatory score $0=0-10$ mononuclear leukocytes per hpf (ML/hpf) within mucosa; $1=11-20$ $\mathrm{ML} / \mathrm{hpf}$ within mucosa; $2=21-30 \mathrm{ML} / \mathrm{hpf}$ within mucosa or 11-20 ML/hpf with extension below muscularis mucosae; $3=31-40 \mathrm{ML} / \mathrm{hpf}$ within mucosa or $21-30$ $\mathrm{ML} / \mathrm{hpf}$ with extension below muscularis mucosa or follicular hyperplasia; $4=>40 \mathrm{ML} / \mathrm{hpf}$ within mucosa or $>30$ $\mathrm{ML} / \mathrm{hpf}$ with extension below muscularis mucosae or follicular hyperplasia. The acute and chronic inflammatory scores were added to give a final histological score. The presence of granulomas was also noted.

In a subset of experiments, SCID mice were treated with a single injection of $200 \mu$ l of anti-TNF antibody (a kind gift from Celltech Therapeutics Ltd., Berkshire, United Kingdom) or isotype antibody $(15 \mathrm{mg} / \mathrm{kg}$ mouse IgG; ICN Biomedicals Inc., Costa Mesa, California, USA) 24 hours before receiving $1 \times 10^{6} \mathrm{SAMP} 1 /$ Yit MLN CD $4^{+}$ T cells. Mice were euthanized 6 weeks later, and the small intestine was histologically evaluated. 


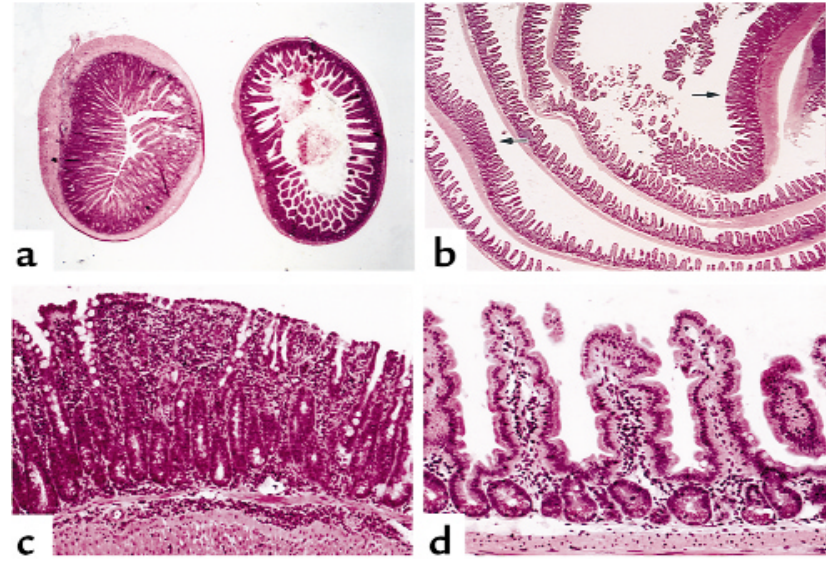

Figure 1

Segmental nature of inflammatory lesions in SAMP1/Yit mice. (a) Sequential transverse sections of small intestine show a relatively normal segment (right section) with intact villous mucosal architecture and a relatively thin muscular layer. The adjacent inflamed segment (left section) shows loss of villous architecture with luminal narrowing and a thickened muscular layer. $\times 40$. (b) Longitudinal section through a Swiss roll of ileum (distal ileum is in center of the roll) showing discrete discontinuous areas of inflammation (arrows) with loss of villous architecture and thickening of the muscular wall. $\times 20$. (c) Higher magnification of the inflamed ileum seen in b. Villi are completely absent in areas. The lamina propria and submucosa are expanded by an inflammatory infiltrate composed of PMNs and mononuclear cells. $\times 150$. (d) Higher magnification of uninflamed mucosa between the two inflammatory foci seen in $\mathbf{b}$. The villi are long and thin; the lamina propria has few lymphocytes; and there is no accumulation of leukocytes in the submucosa or base of the mucosa. The intestinal crypts contain Paneth cells (with prominent cytoplasmic granules) located only at the very base. All panels show staining with hematoxylin and eosin. $\times 225$.

Statistical analysis. Data were analyzed using ANOVA and Schiff's method of multiple comparisons. The Mann-Whitney $U$ test was used for nonparametric data. An $\alpha$ level of $P<0.05$ was considered significant.

\section{Results}

Description of ileitis in SAMP1/Yit mice. Mild to moderate ileitis was first found in SAMP1/Yit mice by 20 weeks of age, and reached $100 \%$ penetrance by 30 weeks. Lesion severity and incidence increased with age. Histological analysis of stomach, liver, kidney, spleen, mesenteric and peripheral lymph nodes, and thymus revealed no significant extraintestinal inflammation. SAMP1/Yit mice exhibited discontinuous areas of transmural intestinal inflammation, most severe in the terminal ileum (Figure 1). Severe inflammatory lesions could be identified by visual inspection as discrete areas of bowel wall thickening and relative stenosis of the lumen. Histological examination revealed mononuclear and PMN cell infiltrates in the lamina propria, submucosa, and muscle layers (Figure 2c). PMNs were found most abundantly in the lamina propria and submucosa. There was focal infiltration of the epithelium by PMNs to form lesions of active cryptitis and crypt microabscesses (Figure 2e), identical to the lesions found in human CD. Many but not all of the inflammatory lesions were associated with Peyer's patches. Early inflammatory lesions consisting of neutrophils causing epithelial damage overlying these preexisting lymphoid aggregates were commonly identified, resembling the aphthoid lesions found in human CD (Figure 2a). Mucosal ulceration and intestinal fistulae were uncommon. The mononuclear cell population consisted of cells morphologically compatible with histiocytes (tissue macrophages), lymphocytes, and plasma cells. Abnormal accumulations of plasma cells could be seen at the base of the mucosa in chronically inflamed areas, compatible with the basal plasmacytosis seen in human chronic inflammatory bowel disease (Figure 2f). In some animals, the tissue macrophages focally coalesced into loose aggregates compatible with granuloma formation (Figure 2d). The normal delicate villous architecture, with a villus/crypt ratio of 4:1 to 5:1, was lost in inflammatory lesions to various degrees by a combination of elongation of the crypts and expansion of the lamina propria (Figure 1c and Figure 2b). This combination of changes lead to areas in the majority of animals that, although not reduced in overall mucosal height, nevertheless had complete loss of villous architecture. In older mice, the severely inflamed areas also showed prominent mucosal fibrosis and distortion of the normally straight crypt architecture in the form of budded and branched glands. In chronically inflamed areas, changes in epithelial phenotype were typically observed in the form of Paneth cell and goblet cell hyperplasia (Figure 2b). The "pyloric metaplasia" commonly seen in human CD was not observed in these animals. Other histological features observed in these mice in common with human CD included muscular and neural hyperplasia of the bowel wall and mucosal lymphangiectasia. Although the colons of these animals never developed grossly identifiable inflammatory lesions, histological examination showed focal areas of mucosal and transmural inflammation in some animals, always of lesser severity than the inflammation found in the terminal ileum. The overall pathological assessment of these animals was a disease process remarkably similar to that seen in human CD.

Composition of LPLs from ileum of 30-week-old SAMP1/Yit mice. Matsumoto et al. previously reported that large numbers of $\mathrm{CD}^{+} \mathrm{T}$ cells infiltrate the ileal lamina pro-

\section{Table 1}

Differences in LPL populations in AKR and SAMP1/Yit mice

\begin{tabular}{lccc}
\hline Phenotype & AKR & SAMP1/Yit & $P$ \\
$\mathrm{CD}^{+}$ & $36.0 \pm 2.5^{\mathrm{A}}$ & $71.8 \pm 6.2$ & $<0.01$ \\
$\mathrm{CD}{ }^{+} \mathrm{CD} 4^{+}$ & $17.0 \pm 2.3$ & $30.9 \pm 3.7$ & $<0.01$ \\
$\mathrm{CD} 3^{+} \mathrm{CD} 8^{+}$ & $18.7 \pm 1.3$ & $42.3 \pm 4.7$ & $<0.01$ \\
$\mathrm{CD} 3^{+} \alpha \beta^{+}$ & $24.3 \pm 4.0$ & $62.1 \pm 5.7$ & $<0.01$ \\
$\mathrm{CD}{ }^{+} \gamma \delta^{+}$ & $9.4 \pm 1.3$ & $9.8 \pm 3.5$ & $\mathrm{NS}$ \\
$\mathrm{CD} 4^{+} \alpha \beta^{+}$ & $14.5 \pm 1.5$ & $30.1 \pm 3.7$ & $<0.01$ \\
$\mathrm{CD} 8^{+} \alpha \beta^{+}$ & $12.5 \pm 1.5$ & $40.0 \pm 6.5$ & $<0.01$ \\
\hline
\end{tabular}

${ }^{A}$ Mean percentage $\pm \mathrm{SEM}, n=15$. NS, not significant. 
Table 2

Percentages of CD69-expressing CD4 ${ }^{+}$and $C D 8^{+}$LPLs from AKR and SAMP1/Yit mice

\begin{tabular}{lccc}
\hline Phenotype & AKR & SAMP1/Yit & $P$ \\
$\mathrm{CD}^{+}$ & $42.0 \pm 7.1^{\mathrm{A}}$ & $78.2 \pm 3.6$ & $<0.01$ \\
$\mathrm{CD}^{+}$ & $62.0 \pm 10.6$ & $95.1 \pm 0.9$ & $<0.01$
\end{tabular}

AMean percentage $\pm \mathrm{SEM}, n=15$.

Table 3

Differences in IEL populations in AKR and SAMP1/Yit mice

\begin{tabular}{lccc}
\hline Phenotype & AKR & SAMP1/Yit & $P$ \\
$\mathrm{CD} 3^{+}$ & $84 \pm 1.7^{A}$ & $81.8 \pm 4.5$ & NS \\
$\mathrm{CD} 3^{+} \mathrm{CD} 4^{+}$ & $7.9 \pm 2.1$ & $11.5 \pm 1.5$ & $\mathrm{NS}$ \\
$\mathrm{CD} 3^{+} \mathrm{CD} 8^{+}$ & $68.7 \pm 2.2$ & $67.9 \pm 4.9$ & $\mathrm{NS}$ \\
$\mathrm{CD} 3^{+} \alpha \beta^{+}$ & $37.2 \pm 4.7$ & $60.5 \pm 6.4$ & $<0.01$ \\
$\mathrm{CD} 3^{+} \gamma \delta^{+}$ & $48.3 \pm 2.0$ & $27.6 \pm 1.6$ & $<0.01$ \\
$\mathrm{CD} 8^{+} \alpha \beta^{+}$ & $31.7 \pm 3.9$ & $52.1 \pm 5.5$ & $<0.01$ \\
$\mathrm{CD} 8^{+} \gamma \delta^{+}$ & $41.7 \pm 2.4$ & $22.9 \pm 1.3$ & $<0.01$
\end{tabular}

AMean percentage \pm SEM, $n=15$. NS, not significant.

pria of SAMP1/Yit mice (10). We have confirmed this result and further characterize the phenotype of these $T$ cells using FACS analysis. Although there was little change in the ratio of $\mathrm{CD}^{+} / \mathrm{CD}^{+} \mathrm{T}$ cells, the percentage of $\mathrm{CD}^{+}{ }^{+} \mathrm{TCR} \alpha \beta^{+}$cells was dramatically increased compared with AKR control mice (Table 1). Furthermore, a greater percentage of TCR $\alpha \beta^{+}$LPLs from SAMP1/Yit mice expressed the activation marker CD69, compared with those harvested from AKR mice (Table 2).

IELs from ileum of SAMP1/Yit mice. IEL populations from the small intestines of SAMP1/Yit and AKR mice were evaluated by flow cytometry. Although there were no differences in the percentages of $\mathrm{CD}^{+}, \mathrm{CD}^{+}$, or $\mathrm{CD} 8 \alpha^{+}$ IELs in SAMP1/Yit mice compared with AKR mice, the percentage of $\mathrm{CD}^{+} \mathrm{CD} 8 \alpha^{+} \mathrm{TCR} \gamma \delta^{+}$cells was dramatically decreased and the percentage of $\mathrm{CD}^{+} \mathrm{CD} 8 \alpha^{+} \mathrm{TCR} \alpha \beta^{+}$ cells was increased proportionately (Table 3 ). A slightly greater percentage of TCR $\alpha \beta^{+}$IELs harvested from SAMP1/Yit mice expressed the activation marker CD69 compared with AKR mice (data not shown).

Adoptive transfer of ileitis by T cells. A large percentage of $\mathrm{T}$ cells harvested from the MLN of SAMP1/Yit mice express a profile of surface markers consistent with an activated phenotype (Figure 3). Adoptive transfer experiments showed that unfractionated MLN cells harvested from SAMP1/Yit mice were capable of transferring ileitis to SCID recipients in a dose- and timedependent manner (Figure 4). Similar results were observed after transfer of CD $4^{+} \mathrm{T}$ cells (Figure 5 ). The most severe ileitis occurred 6 weeks after transfer and was correlated with increasing numbers of transferred $\mathrm{CD}^{+} \mathrm{T}$ cells (Figure 5). Inflammatory infiltrates composed primarily of mononuclear cells with some PMNs could be detected throughout the entire length of the intestinal tract; however, the most severe inflammation occurred in the ileum, where focal villus blunting was observed (Figure 6).

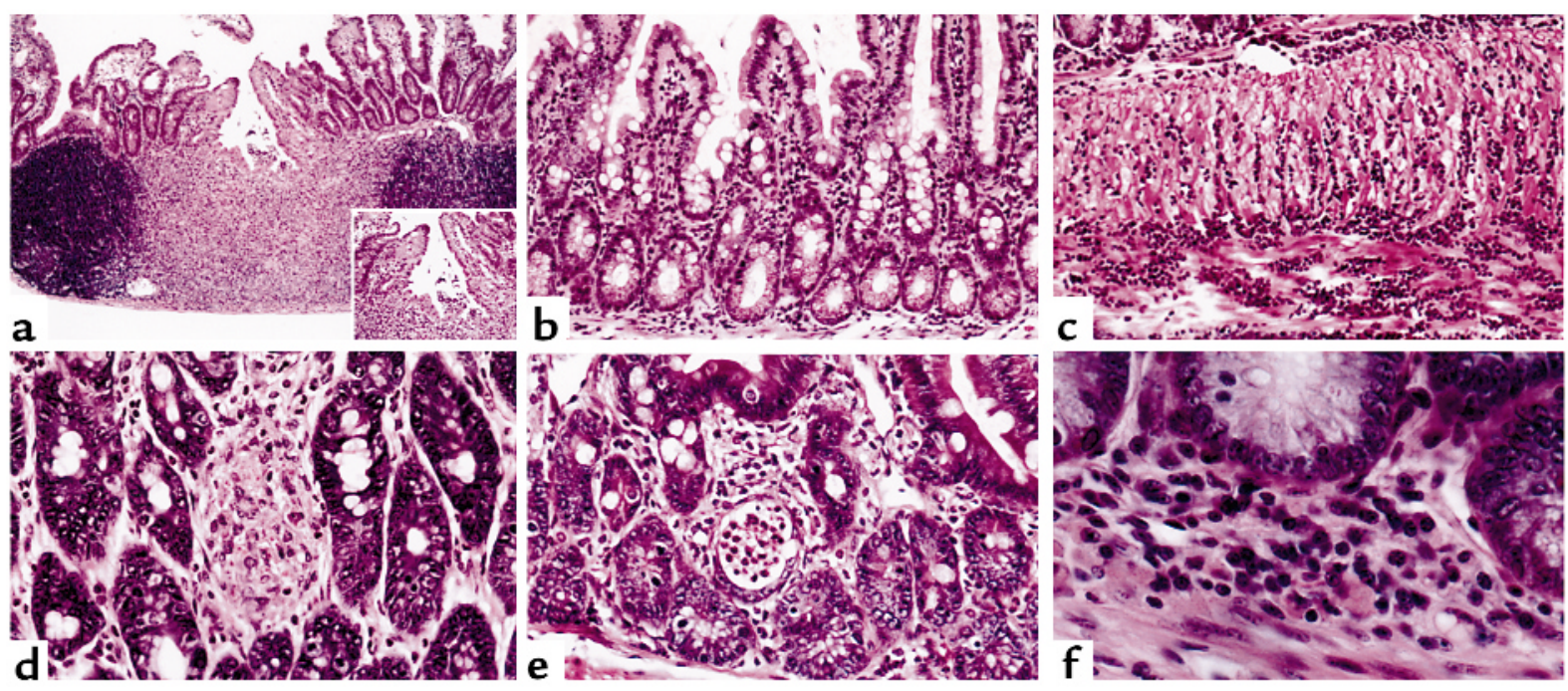

Figure 2

Histological characteristics of intestinal inflammation in SAMP1/Yit mice. (a) An early aphthous inflammatory lesion involving a Peyer's patch. A pre-existing submucosal lymphoid aggregate is involved by a mixed inflammatory infiltrate of PMNs and macrophages. The epithelium overlying this lesion is infiltrated by PMNs and is focally eroded. $\times 80$; inset, $\times 125$. (b) Inflamed small intestinal mucosa showing partial villous blunting and epithelial phenotypic changes. Compared with normal uninflamed mucosa (Figure 1d), there are increased numbers of Paneth cells in the crypts and mucin-secreting goblet cells in the crypts and on the villi. $\times 200$. (c) Transmural inflammation. PMNs and mononuclear cells infiltrate the full thickness of the muscularis propria to involve the serosal surface. $\times 200$. (d) Mucosal granuloma. A collection of epithelioid histiocytes is present within the lamina propria between intestinal crypts. $\times 400$. (e) Active inflammation. PMNs can be seen within the lamina propria, infiltrating between epithelial cells ("cryptitis") and present in aggregate within a crypt lumen ("crypt microabscess"). $\times 200$. (f) Basal plasmacytosis. The base of the inflamed mucosa contains numerous plasma cells, characterized by large cells with eccentrically placed cytoplasm and coarse nuclear chromatin clumping in a "clock face" pattern. All panels show staining with hematoxylin and eosin. $\times 800$. 

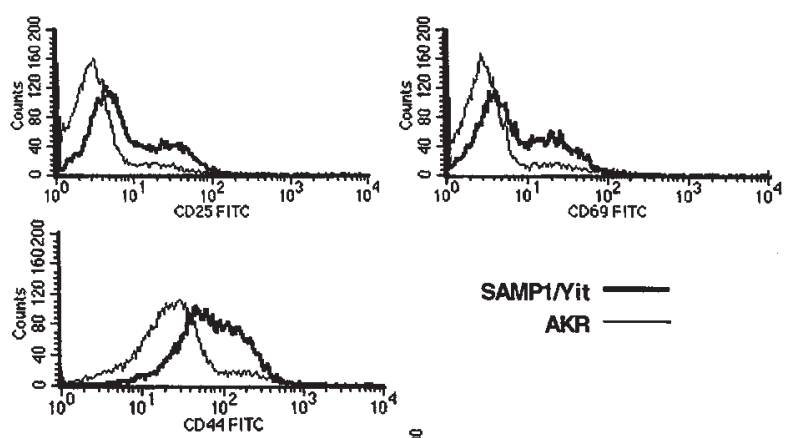

AKR
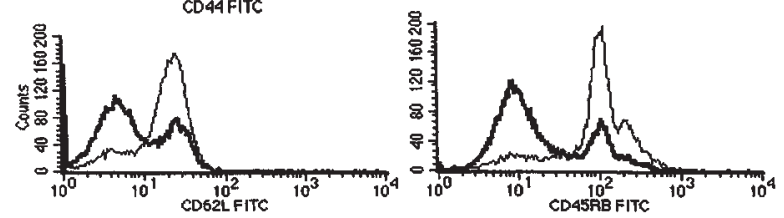

Figure 3

Analysis of surface marker expression by $C D 4^{+} \mathrm{T}$ cells from MLN. $\mathrm{CD}^{+} \mathrm{T}$ cell-enriched MLN cells were harvested from 30-week-old AKR and SAMP1/Yit mice. Cells were analyzed for the expression of CD25, CD69, CD44, CD62L, and CD45RB $(n=8)$.

Cytokines produced by MLNT cells. To determine whether Th1- or Th2-type T cells were responsible for this transfer of ileitis, we measured MLN cytokine production in vitro before and after transfer to SCID mice. IFN- $\gamma$ production by MLN cells from SAMP1/Yit mice was threeto fourfold higher than that seen in AKR mice after 48 hours in culture (Figure 7a). Differences in TNF production were even more dramatic (Figure 7a). AKR MLN cells secreted no detectable TNF, whereas SAMP1/Yit MLN cells secreted significant TNF levels. No IL-4 or IL10 could be detected in cultures of MLN cells from either SAMP1/Yit or AKR mice (data not shown). MLN cells harvested from SCID recipients of SAMP1/Yit cells also produced higher levels of both IFN- $\gamma$ and TNF compared with recipients of AKR control cells (Figure 8).

Pretreatment with anti-TNF antibody prevents ileitis in adoptive transfer recipients. Given that pathogenic T cells from SAMP1/Yit mice produce significant levels of TNF, this cytokine may play an important role in the pathogenesis of ileitis in this model. To test this hypothesis, SCID mice were injected with anti-TNF antibody. Interestingly, anti-TNF antibody administration significantly reduced the severity of ileitis (65\%; $P<0.01)$ compared with mice treated with isotype control antibody (Figure 8).

\section{Discussion}

In the present study, we described the immunologic characteristics of a novel spontaneous murine model of ileitis, the SAMP1/Yit mouse. This model develops inflammatory lesions in the small intestine that are remarkably similar to human Crohn's disease. Salient features of these inflammatory lesions include a discontinuous distribution, with the greatest severity in the terminal ileum, the accumulation of both PMNs and mononuclear cells in the intestinal mucosa, transmural inflammation, the presence of granulomatous structures in a subset of animals, alterations in intestinal mucosal architecture, thickening of the bowel wall, and phenotypic alterations of the intestinal epithelial cell population in chronically inflamed areas.

Our results strongly suggest that human CD patients and SAMP1/Yit mice share similar pathogenic mechanisms of disease. For example, like in human CD, Th1type $\mathrm{T}$ cells appear to be involved in SAMP1/Yit ileitis. Large numbers of activated $T$ cells infiltrate the lamina propria of SAMP1/Yit mice and are associated with accumulations of multinucleated giant cells, forming focal areas of granulomatous inflammation. These granuloma-like structures are most commonly the result of a Th1-mediated immune response and are important hallmarks of CD in humans. Moreover, $\mathrm{T}$ cells harvested from the MLN of SAMP1/Yit mice with severe ileitis produce significant amounts of the Th1 cytokines, IFN- $\gamma$ and TNF, in culture. These same cells can transfer ileitis to SCID recipients and continue to produce significant levels of Th1-type cytokines after transfer. Importantly, unlike the lesions found in the CD45RB transfer model of colitis $(6,7)$, the inflammation seen in SCID mice adoptively transferred with SAMP1/Yit MLN T cells is primarily localized to the

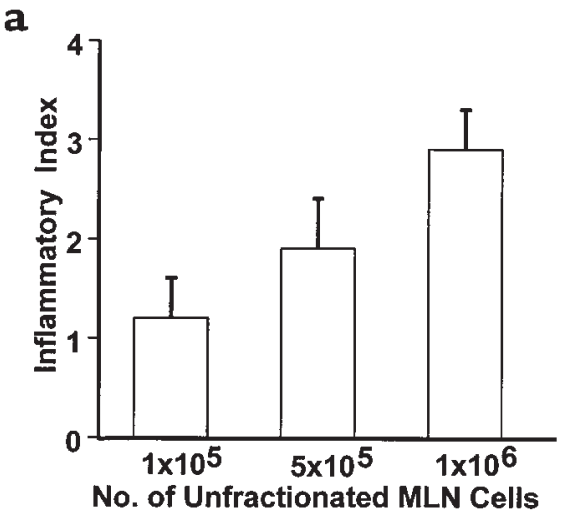

b

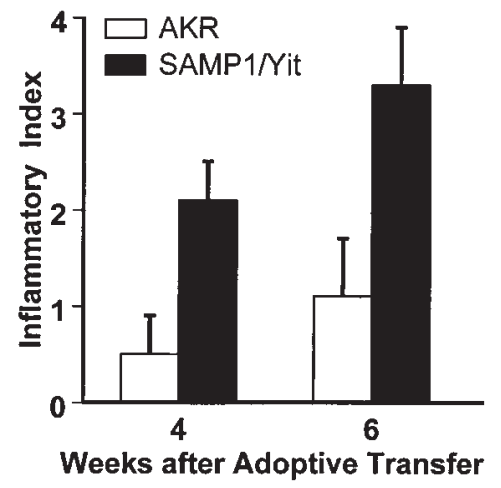

Figure 4

Severity of ileitis after adoptive transfer of unfractionated MLN cells. (a) Dose response of MLN cells from 30-week-old SAMP1/Yit mice, 6 weeks after transfer. (b) Time course of response to transferred MLN cells. SCID mice received $1 \times 10^{6} \mathrm{AKR}$ or SAMP1/Yit MLN cells. Data are presented as mean $\pm \operatorname{SEM}(n=12)$. 

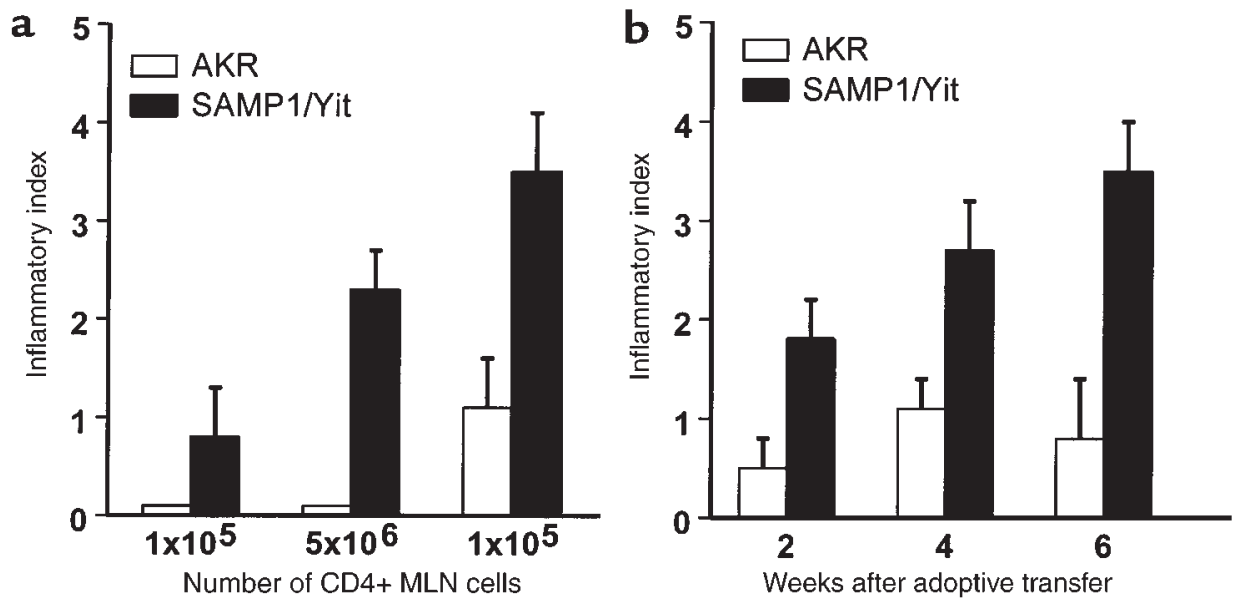

\section{Figure 5}

Severity of ileitis after adoptive transfer of $\mathrm{CD}^{+} \mathrm{MLN}$ cells. (a) Dose response of transferred $\mathrm{CD}^{+} \mathrm{MLN}$ cells from 30-week-old AKR and SAMP1/Yit mice, 6 weeks after transfer. (b) Time course of response to transferred $\mathrm{CD}^{+}$ MLN cells. SCID mice received $1 \times 10^{6}$ AKR or SAMP1/Yit MLN cells. Data are presented as mean $\pm \operatorname{SEM}(n=16)$.

terminal ileum and exhibits histopathology that is very similar to the spontaneous disease seen in the SAMP1/Yit mice. These results strongly suggest that MLN T cells from SAMP1/Yit mice may recognize antigen found exclusively in the terminal ileum. Such antigens could be expressed by resident intestinal bacteria specifically localized to the terminal ileum or ileal-specific self-antigens that cross-react with antigens expressed by natural gut flora.

Interestingly, the small intestines of SAMP1/Yit mice have an altered composition of IELs. The percentage of CD $8 \alpha^{+} \mathrm{TCR} \gamma \delta^{+} \mathrm{T}$ cells is dramatically decreased in SAMP1/Yit mice compared with age-matched AKR control mice, whereas the CD $8 \alpha^{+} \mathrm{TCR} \alpha \beta^{+}$population is increased proportionately. Although still controversial, several functions for IELs in healthy individuals have been proposed, including mucosal defense against microbial invasion, support of epithelial cell growth and repair, immunoregulation, and maintenance of the general homeostasis of the intestinal mucosal immune system $(12,13)$. Because TCR $\gamma \delta^{+}$knockout mice do not develop colitis, it is unlikely that the decrease in $\mathrm{TCR} \gamma \delta^{+}$cells in SAMP1/Yit mice is directly related to the initiation of ileitis (14). However, given that the cause of this disease is likely to be multifactorial, it is possible that a decrease in this cell population could result in exacerbation of a chronic inflammatory response initiated by another mechanism(s). This possibility needs further investigation.

TNF appears to play an important, though unclear, role in many inflammatory diseases, including CD (15, 16). We show in the present study that TNF also

\section{Figure 6}

Histological features of ileitis adoptively transferred to SCID recipients by $\mathrm{CD}^{+} \mathrm{T}$ cells from MLN of SAMP1/Yit or AKR mice. Disease was localized primarily to the ileum, but was also detectable in the duodenum. (a) Representative ileum from a SCID mouse 6 weeks after transfer of AKR control cells shows normal structure of the intestinal mucosa with mild infiltration of inflammatory cells. (b) lleum from a SCID mouse 6 weeks after transfer of SAMP1/Yit cells shows severe mucosal damage with heavy infiltration of $\mathrm{PMN}$ and mononuclear cells. appears to be involved in the pathogenesis of ileitis in SAMP1/Yit mice. A single injection of a neutralizing anti-TNF antibody significantly attenuates ileitis in SCID mice 6 weeks after transfer of pathogenic CD4 ${ }^{+}$ $\mathrm{T}$ cells from SAMP1/Yit mice. These findings strongly suggest that TNF may be involved in the initial activation and homing of pathogenic $T$ cells during chronic intestinal inflammation and may explain the long-term remission seen in patients with Crohn's disease after a single infusion of anti-TNF therapy (17). These results further suggest that SAMP1/Yit mice develop ileal lesions through pathogenic mechanisms very similar to those leading to human Crohn's disease.

Murine models of IBD suitable for investigating disease pathogenesis have only recently become available.

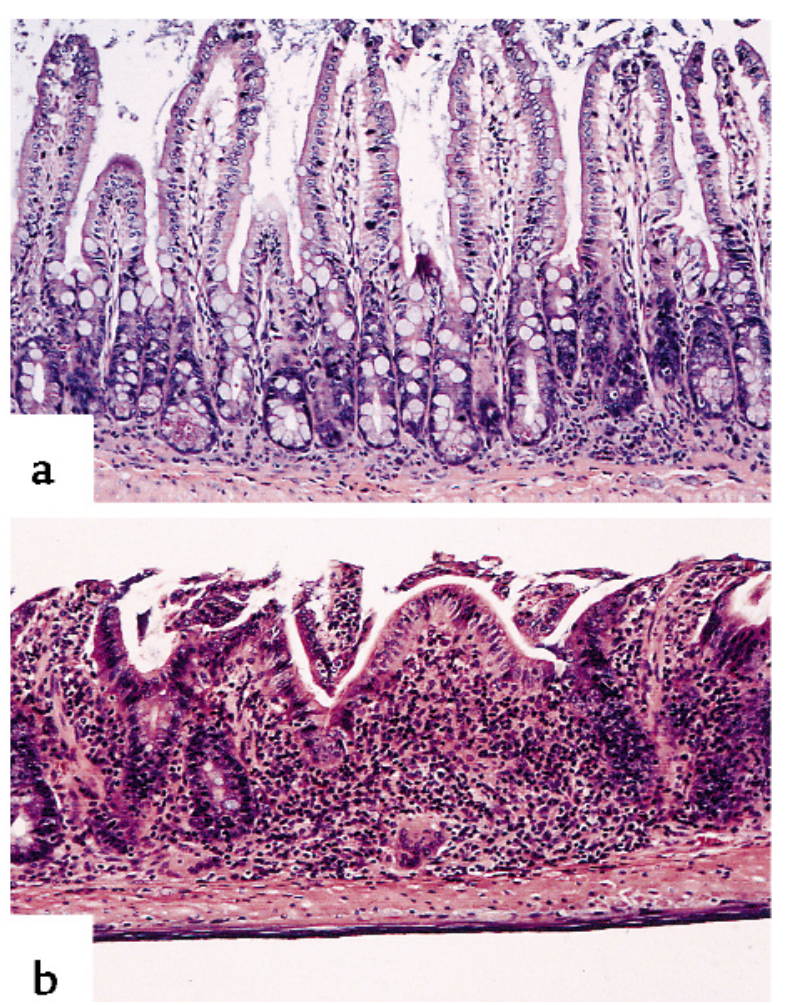


a

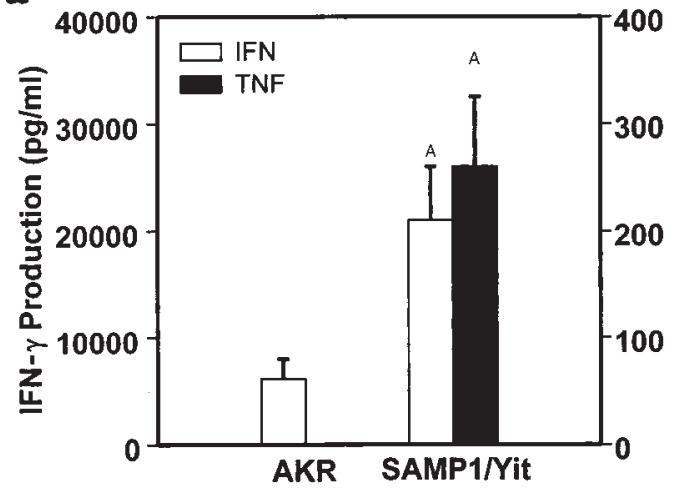

b

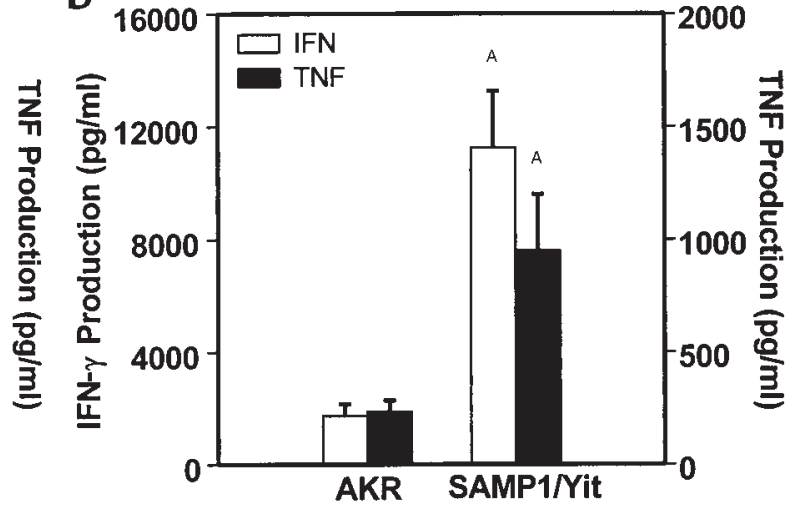

\section{Figure 7}

Cytokine production by MLN cells from SAMP1/Yit mice and from SCID recipients of SAMP $1 /$ Yit MLN CD4 ${ }^{+} \mathrm{T}$ cells. MLN cells $\left(1 \times 10^{6} / \mathrm{ml}\right)$ were cultured with immobilized anti-CD3, and secreted IFN- $\gamma$ and TNF were measured by specific ELISA. (a) Cytokine production from MLN isolated from 30-week-old AKR or SAMP1/Yit mice. (b) Cytokine production from SCID recipients 6 weeks after transfer of MLN CD4 ${ }^{+} T$ cells from AKR or SAMP1/Yit mice. Data are presented as mean $\pm \operatorname{SEM}(n=18)$. ${ }^{A} P<0.01$.

The majority of these models have been created either by deleting immune-related molecules or other transgenic manipulations, and include TCR- $\alpha$ and $-\beta$, IL10 , IL-2, IL-2 receptor, and G $\alpha$ i2 (G protein) knockout mice, as well as TNF $\Delta$ ARE and Tge $\beta 26$ (human $\beta$ protein of CD3 complex) transgenic mice $(14,18-29)$. With the exception of IL-10-deficient and TNF $\triangle$ ARE mice, these animals develop a chronic colitis without involvement of the terminal ileum (9). Furthermore, although these models have been instrumental in identifying immune components that are involved in mucosal immunoregulation, it is unlikely that these targeted mutations are the underlying defect in human IBD. These models are, therefore, somewhat limited in their application toward understanding the etiopathogenesis of IBD.

Two murine models of $\mathrm{T}$ cell-mediated colitis that do not involve direct genetic manipulation have also been widely studied. The first involves CD45RB hi $\mathrm{T}$ cell transfer into SCID mice (30-36). The resulting colitis is severe and mediated primarily by IFN- $\gamma$ and to a lesser extent by TNF. The second is a hapteninduced colitis model, wherein mice are given intrarectal treatments with 2,4,6-trinitrobenzene sulfonic acid (TNBS) and develop a delayed hypersensitivity-like response (37-41). Both of these models have provided very useful information, including significant evidence of a role for Th1 $\mathrm{T}$ cells in colitis. However, to understand fully the mechanisms that initiate and maintain intestinal inflammation in IBD, it is useful to study the disease as it develops spontaneously without molecular, chemical, or immunologic manipulations. To date, to our knowledge only two spontaneous models of intestinal inflammation have been described; namely, the cotton-top tamarin and the murine $\mathrm{C} 3 \mathrm{H} / \mathrm{HeJBir}$ model of colitis. Both of these models resemble ulcerative colitis rather than $\mathrm{CD}$. Although the $\mathrm{C} 3 \mathrm{H} / \mathrm{HeJBir}$ model has provided useful information concerning some aspects of the pathogenesis of IBD, the disease localizes to the colon and does not involve the ileum or other parts of the small intestine $(7,42-45)$. Although significant progress has been made in understanding some of the mechanisms involved in intestinal inflammation using these models, there is still a definite need for a model that displays the complexities specific to CD. The spontaneous nature of the intestinal lesion found in SAMP1/Yit mice, along with their remarkable resemblance to human $\mathrm{CD}$, as well as similarities in associated immune responses, makes this model a unique and very promising tool for studying the etiopathogenesis of human CD.

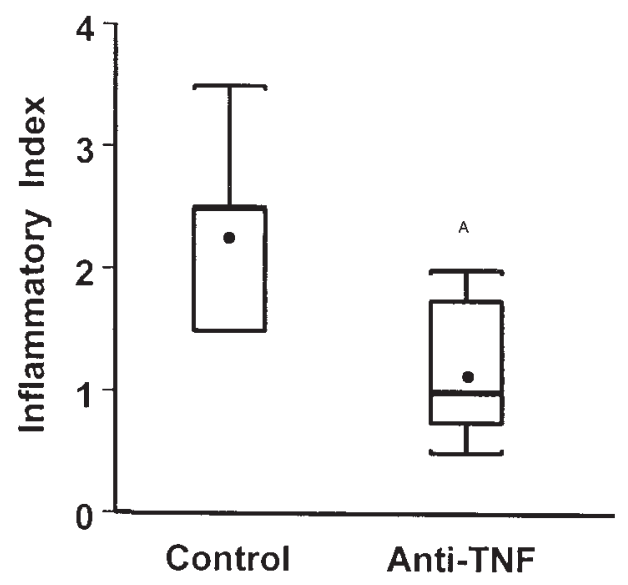

Figure 8

Anti-TNF antibody treatment of ileitis adoptively transferred to SCID recipients by $C D 4^{+} T$ cells from the MLN of SAMP1/Yit mice. SCID mice were treated with a single injection of anti-TNF or isotype control antibody prior to adoptive transfer of $1 \times 10^{6} \mathrm{MLN} \mathrm{CD4}{ }^{+} \mathrm{T}$ cells from SAMP1/Yit mice. Severity of inflammation was evaluated 6 weeks after transfer using a semiquantitative scoring system. Black circle, mean; heavy black line, median; box, interquartile range; error bars, $95 \%$ confidence interval. ${ }^{A} P<0.01$. 


\section{Acknowledgments}

We are grateful to Marcia Bentz and Meha Shah for expert technical assistance. We also thank Kristen Arseneau for her critical review of the manuscript. This work was supported by a Career Development Award from the Crohn's and Colitis Foundation of America and a Research and Development Award from the University of Virginia (to M.M. Kosiewicz), and US Public Health Service/NIH grants DK-42191, DK-55812 and DK-57880 (to F. Cominelli).

1. Podolsky, D.K. 1991. Inflammatory bowel disease. N. Engl. J. Med. 325:928-937.

2. Satsangi, J., Jewell, D., Parkes, M., and Bell, J. 1998. Genetics of inflammatory bowel disease. A personal view on progress and prospects. Dig. Dis. 16:370-374.

3. Satsangi, J., et al. 1996. Contribution of genes of the major histocompatibility complex to susceptibility and disease phenotype in inflammatory bowel disease. Lancet. 347:1212-1217.

4. Duerr, R.H. 1996. Genetics of inflammatory bowel disease. Inflamm. Bowel Dis. 2:48-60.

5. Papadakis, K.A., and Targan, S.R. 1999. Current theories on the cause of inflammatory bowel disease. Gastroenterol. Clin. North Am. 28:283-296.

6. Blumberg, R.S., Saubermann, L.J., and Strober, W. 1999. Animal models of mucosal inflammation and their relationship to human inflammatory bowel disease. Curr. Opin. Immunol. 11:648-656.

7. Elson, C.O., Sartor, R.B., Tennyson, G.S., and Riddell, R.H. 1995. Experimental models of inflammatory bowel disease. Gastroenterology. 109:1344-1367.

8. Bhan, A.K., Mizoguchi, E., Smith, R.N., and Mizoguchi, A. 1999. Colitis in transgenic and knockout animals as models of human inflammatory bowel disease. Immunol. Rev. 169:195-207.

9. Pizarro, T.T., Arseneau, K.O., and Cominelli, F. 2000. Lessons from genetically-engineered animal models XI. Novel mouse models to study pathogenic mechanisms of Crohn's disease. Am. J. Physiol. 278:G665-G669.

10. Matsumoto, S., et al. 1998. Inflammatory bowel disease-like enteritis and caecitis in a senescence accelerated mouse P1/Yit strain. Gut. 43:71-78.

11. Kozaiwa, K., Kosiewicz, M.M., Moskaluk, C.A., Cominelli, F., and McDuffie, M.J. 2000. Lack of linkage between MHC haplotype and ileitis in a spontaneous model of Crohn's disease. Gastroenterology. 118:A334. (Abstr.)

12. Beagley, K.W., and Husband, A.J. 1998. Intraepithelial lymphocytes: origins, distribution, and function. Crit. Rev. Immunol. 18:237-254.

13. Kagnoff, M.F. 1998. Current concepts in mucosal immunity. III. Ontogeny and function of gamma delta $\mathrm{T}$ cells in the intestine. Am. J. Physiol. 274:G455-G458.

14. Mombarerts, P., et al. 1993. Spontaneous development of inflammatory bowel disease in T cell receptor mutant mice. Cell. 75:274-282.

15. Kollias, G., Douni, E., Kassiotis, G., and Kontoyiannis, D. 1999. On the role of tumor necrosis factor and receptors in models of multiorgan failure, rheumatoid arthritis, multiple sclerosis and inflammatory bowel disease. Immunol. Rev. 169:175-194.

16. Kollias, G., Douni, E., Kassiotis, G., and Kontoyiannis, D. 1999. The function of tumour necrosis factor and receptors in models of multi-organ inflammation, rheumatoid arthritis, multiple sclerosis and inflammatory bowel disease. Ann. Rheum. Dis. 58(Suppl. 1):132-139.

17. Rutgeerts, P., et al. 1999. Efficacy and safety of retreatment with anti-tumor necrosis factor antibody (infliximab) to maintain remission in Crohn's disease. Gastroenterology. 117:761-769.

18. Mitzoguchi, A., Mizoguchi, E., Tonegawa, S., and Bhan, A.K. 1996. Alteration of a polyclonal to an oligoclonal immune response to cecal aerobic bacterial antigens in TCR $\alpha$ mutant mice with inflammatory bowel disease. Int. Immunol. 8:1387-1394.

19. Mizoguchi, A., et al. 1996. Cytokine imbalance and autoantibody production in TCR $\alpha$ mutant mice with inflammatory bowel disease. J. Exp. Med. 183:847-856

20. Davidson, N.J., et al. 1996. T helper cell 1-type CD4+ T cells, but not B cells, mediate colitis in interleukin 10-deficient mice. J. Exp. Med. 184:241-251.

21. Kuhn, R., Lohler, J., Rennick, D., Rajewsky, K., and Muller, W. 1993. Interleukin-10-deficient mice develop chronic enterocolitis. Cell. 75:263-274.
22. Sadlack, B., et al. 1993. Ulcerative colitis-like disease in mice with a disrupted interleukin-2 gene. Cell. 75:253-261.

23. Simpson, S.J., Mizoguchi, E., Allen, D., Bhan, A.K., and Terhorst, C. 1995. Evidence that $\mathrm{CD}^{+}$, but not $\mathrm{CD}^{+} \mathrm{T}$ cells are responsible for murine interleukin-2-deficient colitis. Eur. J. Immunol. 25:2618-2625.

24. Raziwolf, Z., Hollander, G.A., and Reiser, H. 1996. Activation of CD4+ T lymphocytes from interleukin 2-deficient mice by costimulatory B7 molecules. Proc. Natl. Acad. Sci. USA. 93:2903-2908.

25. Willerford, D.M., et al. 1995. Interleukin-2 receptor alpha chain regulates the size and content of the peripheral lymphoid compartment. Immunity. 3:521-530.

26. Rudolph, U., et al. $1995 . \mathrm{G}_{\mathrm{i} 2} \alpha$ protein deficiency: a model of inflammatory bowel disease. J. Clin. Immunol. 15(Suppl.):101S-105S.

27. Rudolph, U., et al. 1995. Ulcerative colitis and adenocarcinoma of the colon

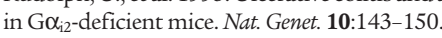

28. Hollander, G.A., et al. 1995. Severe colitis in mice with aberrant thymic selection. Immunity. 3:27-38.

29. Kontoyiannis, D., Pasparakis, M., Pizarro, T.T., Cominelli, F., and Kollias, G. 1999. Impaired on/off regulation of TNF biosynthesis in mice lacking TNF AU-rich elements: implications for joint and gut-associated immunopathologies. Immunity. 10:387-398.

30. Rudolphi, A., Bonhagen, K., and Reimann, J. 1996. Polyclonal expansion of adoptively transferred $\mathrm{CD}^{+}$alpha beta $\mathrm{T}$ cells in the colonic lamina propria of scid mice with colitis. Eur. J. Immunol. 26:1156-1163.

31. Powrie, F., Leach, M.W., Mauze, S., Caddle, L.B., and Coffman, R.L. 1993. Phenotypically distinct subsets of $\mathrm{CD}^{+} \mathrm{T}$ cells induce or protect from chronic intestinal inflammation in C. B-17 scid mice. Int. Immunol. 5:1461-1471.

32. Powrie, F., et al. 1994. Inhibition of Th1 responses prevents inflammatory bowel disease in scid mice reconstituted with CD4RBhi CD4 ${ }^{+} \mathrm{T}$ cells. Immunity. 1:553-562.

33. Powrie, F., Carlino, J., Leach, M.W., Mauze, S., and Coffman, R.L. 1996. A critical role for transforming growth factor-beta but not interleukin 4 in the suppression of $\mathrm{T}$ helper type 1-mediated colitis by CD45RB(low) CD4+ T cells. J. Exp. Med. 183:2669-2674.

34. Rudolphi, A., Boll, G., Poulsen, S.S., Claesson, M.H., and Reimann, J. 1994. Gut-homing CD4+ TCR $\alpha \beta^{+}$T cells in the pathogenesis of murine inflammatory bowel disease. Eur. J. Immunol. 24:2803-2812.

35. Powrie, F. 1995. T cells in inflammatory bowel disease: protective and pathogenic roles. Immunity. 3:171-174.

36. Powrie, F., Correa, O.R., Mauze, S., and Coffman, R.L. 1994. Regulatory interactions between DC4RBhigh and CD45RBlow $\mathrm{CD}^{+} \mathrm{T}$ cells are important for the balance between protective and pathogenic cell-mediated immunity. J. Exp. Med. 179:589-600.

37. Duchmann, R., Schmitt, E., Knolle, P., Meyer zum Buschenfelde, K.H., and Neurath, M. 1996. Tolerance towards resident intestinal flora in mice is abrogated in experimental colitis and restored by treatment with interleukin-10 or antibodies to interleukin-12. Eur. J. Immunol. 26:934-938.

38. Neurath, M.E., et al. 1996. Experimental granulomatous colitis in mice is abrogated by induction of TGF $\beta$-mediated oral tolerance. J. Exp. Med. 183:2605-2616.

39. Stuber, E., Strober, W., and Neurath, M. 1996. Blocking the CD40L-CD40 interaction in vivo specifically prevents the priming of $\mathrm{T}$ helper 1 cells through the inhibition of interleukin-12 secretion. J. Exp. Med. 183:693-698.

40. Elson, C.O., et al. 1996. Hapten-induced model of murine inflammatory bowel disease-mucosal immune responses and protection by tolerance. $J$. Immunol. 157:2174-2185.

41. Neurath, M.F., Fuss, I., Kelsall, B.L., Stuber, E., and Strober, W. 1995. Antibodies to interleukin 12 abrogate established experimental colitis in mice.J. Exp. Med. 182:1281-1290.

42. Ni, J., Chen, S.F., and Hollander, D. 1996. Immunological abnormality in $\mathrm{C} 3 \mathrm{H} / \mathrm{HeJ}$ mice with heritable inflammatory bowel disease. Cell. Immunol. 169:7-15.

43. Sundberg, J.P., Elson, C.O., Bedigian, H., and Birkenmeier, E.H. 1994. Spontaneous, heritable colitis in a new substrain of $\mathrm{C} 3 \mathrm{H} / \mathrm{HeJ}$ mice. Gastroenterology. 107:1726-1735.

44. Cong, Y., et al. 1998. CD4+ T cells reactive to enteric bacterial antigens in spontaneously colitic $\mathrm{C} 3 \mathrm{H} / \mathrm{HeJBir}$ mice: increased $\mathrm{T}$ helper cell type 1 response and ability to transfer disease. J. Exp. Med. 187:855-864.

45. Brandwein, S.L., et al. 1997. Spontaneously colitic C3H/HeJBir mice demonstrate selective antibody reactivity to antigens of the enteric bacterial flora. J. Immunol. 159:44-52. 